\title{
https://doi.org/10.48009/1_iis_2005_66-72 \\ AN EXPLORATORY INVESTIGATION OF THE EFFECT ON LEARNING OUTCOMES OF DIFFERENT TYPES OF PRESENTATION HANDOUTS
}

\author{
Vic Matta, Ohio University, matta@ohio.edu \\ Raymond Frost, Ohio University, frostR@ohio.edu \\ Wayne Huang, Ohio University, huangW@ohio.edu
}

\begin{abstract}
This paper presents the results of a study of the efficacy of handouts provided during a classroom presentation. Keeping the duration of our lecture constant, we study the effect of various types of handouts on the learning outcomes achieved by the students on a multiple choice quiz administered during a subsequent session. The research findings show that students learn more when provided with a handout that includes optimized slide thumbnails and the presenter's notes.
\end{abstract}

Keywords: Customized handouts, PowerPoint, presentation notes, efficacy of handouts, classroom presentation, learning outcome

\section{INTRODUCTION}

Pedagogical studies in the past have focused on dimensions of learning processes (such as interactivity, cognitive and metacognitive events [1] and learning outcomes with independent variables (like duration, rate of delivery, and timing of lectures). However, there is not much research on the efficacy of various types of handouts provided during a presentation-especially a PowerPoint presentation. PowerPoint is a de facto standard in higher education. PowerPoint slides regularly accompany textbooks or are generated by instructors. However, there is a lot of variability as to what is handed to the students during a presentation. Some instructors hand out nothing whereas others handout slide thumbnails. Fewer still handout slide thumbnails together with their lecture notes.

We study the effects of different types (or levels) of handouts provided to four groups (or classes) of students during a twenty minute presentation. The results are analyzed using parametric procedures for repeated measures on four independent samples.

\section{LITERATURE REVIEW}

A handout, as a tool to facilitate students' learning, is used to a greater or lesser extent in almost every discipline-e.g., medicine, engineering, science and information technology (computer science or information systems) $[2,3,4,5,7]$.

Prior research shows how handouts were used to facilitate learning in different ways, such as studying the effects of distributing handouts during a speech on receivers' inferred information 
processing [6]. Another study explored how patients react to a computer-generated handout that was developed in response to feedback from a focus group [8].

In a study conducted in a UK medical school, researchers studied the effectiveness of two different ways of presenting information (using different versions of a handout) on learning outcomes [9]. The results of that study were not statistically significant.

Our comprehensive literature search reveals no study of the effects of presentation handouts on learning outcomes in information systems education.

\section{CASE STUDY}

\section{Description of the Case:}

The research was conducted in an MIS class of freshman and sophomore level students at a large public university in the Midwest. The topic of the lecture was Graphical File Formats in the context of Photoshop and the World Wide Web. The presentation supported the discussion of file formats with multiple visual examples. In order to maximize learning, we limited the presentation to twenty minutes and twenty PowerPoint slides. The same guest lecturer delivered the same presentation to four classes of students over two days. Each class was given a different treatment (or handout) as described below. For convenience, these will be referred to as Groups 1 through 4. Due to the exploratory nature of this study, a sample size of 120 (30 per class) was used. We assume random assignment of students to treatment groups since the classes follow a common syllabus. All handouts were distributed at the beginning of the lecture.

1. The Control Group: The first class was the control group and did not receive any handouts, though students could opt to take their own notes.

2. Six Slide Handout: The second class received handouts printed from PowerPoint with six slides to a page.

3. Three Slide Handout: The third class received handouts printed from PowerPoint but with only three slides to a page, and lined space for taking notes alongside each slide.

4. Optimized Handout with Speaker's Notes: The fourth class received handouts produced using the Send to Word option in PowerPoint. These handouts place the speaker's notes alongside each slide. Within Word, the handout was further customized to increase the size of each slide thumbnail to enhance readability.

The handouts are reproduced in Figure 1 at actual size. Note how difficult it is to read text on the thumbnails of all but the optimized thumbnail. Microsoft could easily improve PowerPoint by generating larger thumbnails on handouts. Note further that the notes typically contain many more words than will fit on a slide, and present this information in complete paragraphs and sentences. This may well facilitate study between the lecture and the quiz. 

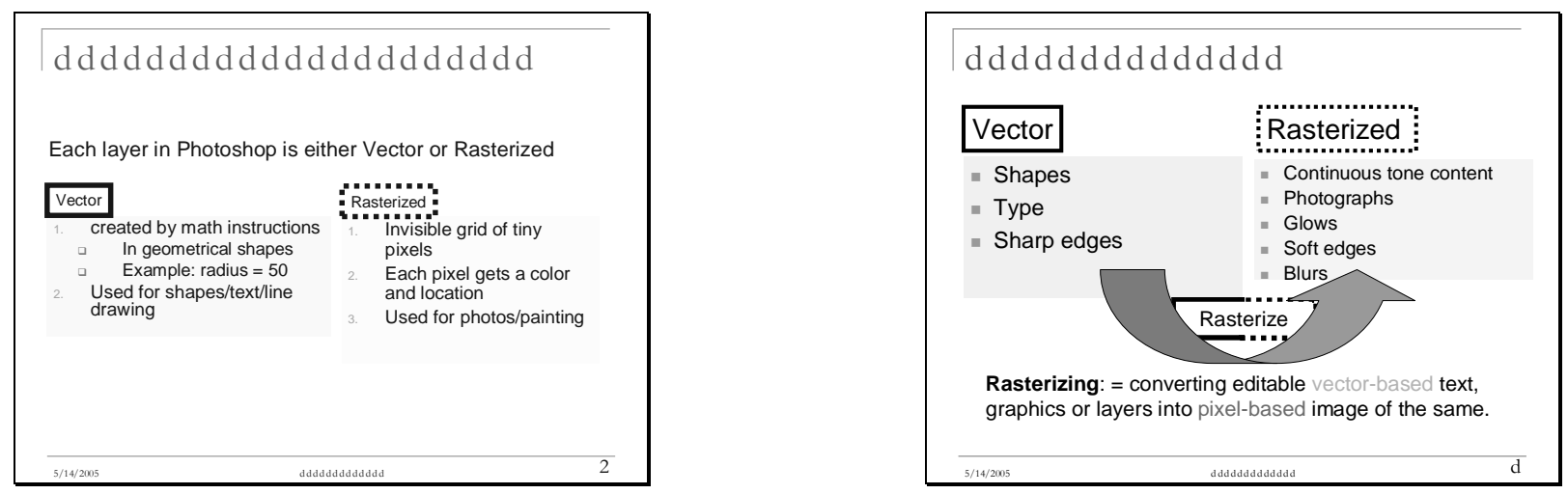

Handout with six slides to a page

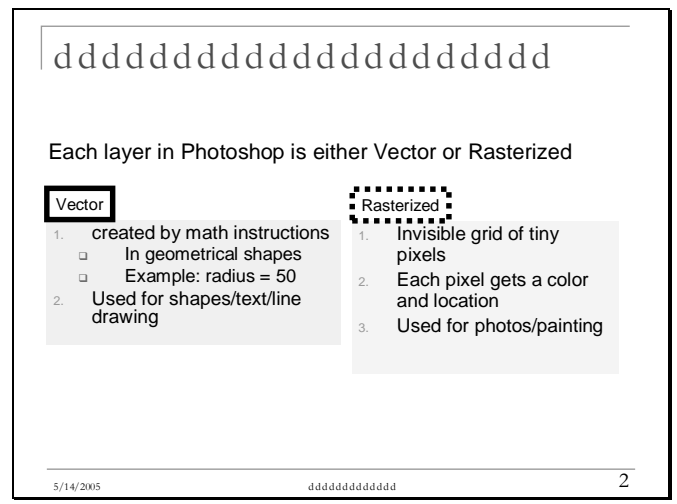

Handout with three slides per page and lined space for notes

\section{dddddddddddddddddddd}

Each layer in Photoshop is either Vector or Rasterized

Vector
1. created by math instructions
$\square \quad$ In geometrical shapes
$\square \quad$ Example: radius $=50$
2. Used for shapes/text/line
drawing

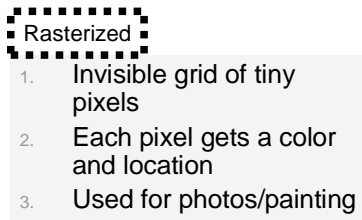

$1 / 2 \mathrm{~d} / 2005$
Photoshop stores artwork either as vector art or a raster graphic. Normally vector art is preferable since it enlarges smoothly. The reason it enlarges so smoothly is that the dimensions and shape of the artwork are stored as math instructions. Enlarging simply involves increasing the dimensions. However, some subjects, such as photos and paintings can only be stored as a raster graphic.

\section{Handout with three optimized slides per page and instructor's notes}

Figure 1. Screenshots showing one row from each of the three types of handouts 


\section{Assessment of Learning Outcomes}

Learning outcomes of this study were assessed by measuring the students' performance on a multiple choice quiz, administered one week after the lecture. This was a twenty point quiz, ten of which were based on this lecture. The subjects were allowed to assume that the quiz would encompass topics covered in class over eight hours of instruction during two weeks. One class (Group \#2), who received the handout with six slides per page, was inadvertently informed by the instructor that half the quiz (ten out of twenty questions) would be based on the twenty minute lecture in question. No other class was given this kind of focus. To the other classes, this lecture was presented as a normal part of the course.

In spite of the advantage afforded Group \#2, the study still produced statistically significant results. To maintain fairness to the students who did not receive any handouts or less developed ones, performance on the ten questions was not counted for grading purposes.

\section{STATISTICAL ANALYSIS}

The quantitative nature of the data permits us to perform a parametric analysis. We corroborate our assumptions below with descriptive statistics.

\section{Assumptions}

1. Independence: The sample groups used in this study are independent. The scores attained by one group in no way affect those received by the other groups being studied. The groups were assigned different treatments at random.

2. Randomness: There is no bias between the classes. That is, students are in a class at random. One class of students is not better in any way than another in this study.

3. Homogeneity of Variance: The four groups of students in the lecture are assumed to have equal levels of variance in achievement.

4. Normally Distributed Groups: The student populations from which the groups are derived are normally distributed as seen in the box plot in Figure 2.

5. Controlled Experiment: The only variation in treatments is the handout. That is,

a. the same instructor presented the material to all four classes

b. the duration and content of presentation and the quiz used for assessment were held constant. 


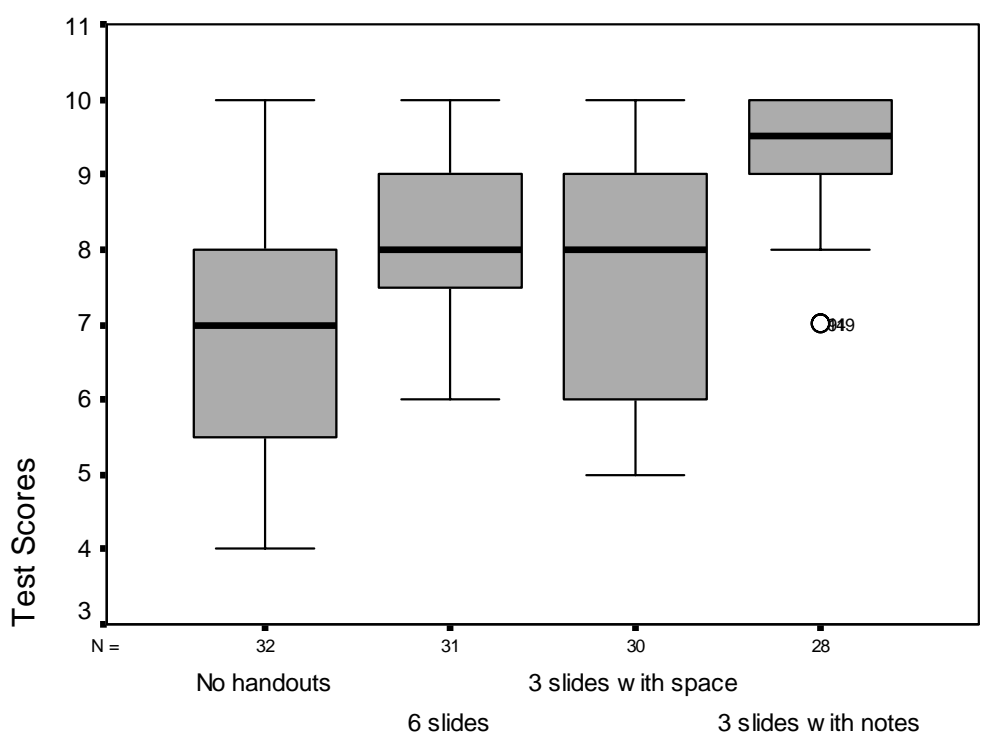

Figure 2. Box plot showing distributions of test scores amongst the four groups

\section{Hypothesis}

The mean learning outcome for the four handouts is exactly the same. There is no difference between the mean levels of achievement of the four groups being tested.

$$
\begin{aligned}
& \mathrm{H}_{0}: \mu_{1}=\mu_{2}=\mu_{3}=\mu_{4} \\
& \mathrm{H}_{\mathrm{a}}: \mu_{\mathrm{i}} \neq \mu_{\mathrm{k}} \text { for some } \mathrm{i}, \mathrm{k}
\end{aligned}
$$

The level of significance set $a$ priori for testing this hypothesis is $\alpha=0.05$.

\section{Criterion for Rejecting $\mathbf{H}_{0}$}

The test statistic for a one-way analysis of variance is the F ratio. Tukey's post-hoc procedures are used to find where the differences lie.

\section{Results and Observations}

The mean learning outcome of the four handouts is not the same and the null hypothesis must be rejected. A one-way ANOVA reveals a between-groups F statistic of 15.061, and a statistical significance $\mathrm{p}=.000(\alpha=0.05)$, as seen in Table 1 below.

Table 1. F test

\begin{tabular}{lccccc}
\multicolumn{1}{c}{ Test Scores } & $\begin{array}{c}\text { Sum of } \\
\text { Squares }\end{array}$ & df & Mean Square & F & Sig. \\
\hline Between Groups & 90.035 & 3 & 30.012 & 15.061 & $\mathbf{. 0 0 0}$ \\
Within Groups & 233.138 & 117 & 1.993 & & \\
Total & 323.174 & 120 & &
\end{tabular}

Tukey's HSD post-hoc analysis reveals exactly where the differences lie by doing multiple pairwise comparisons between the scores on the quiz for the four classes. 
Table 2. Dependent Variable: Test Scores using Tukey HSD

\begin{tabular}{|c|c|c|c|}
\hline (I) Groups & (J) Groups & $\begin{array}{c}\text { Mean } \\
\text { Difference }\end{array}$ & $\begin{array}{r}\text { Std } \\
\text { Erro }\end{array}$ \\
\hline
\end{tabular}

\begin{tabular}{|c|c|c|c|c|c|c|}
\hline & & & & & $\begin{array}{l}\text { Lower } \\
\text { Bound }\end{array}$ & $\begin{array}{l}\text { Upper } \\
\text { Bound }\end{array}$ \\
\hline \multirow[t]{3}{*}{ No handouts } & 6 slides & $-1.35(*)$ & .356 & .001 & -2.28 & -.42 \\
\hline & 3 slides with space & -.72 & .359 & .188 & -1.66 & .21 \\
\hline & 3 slides with notes & $-2.37(*)$ & .365 & .000 & -3.32 & -1.42 \\
\hline \multirow{3}{*}{6 slides } & No handouts & $1.35\left(^{*}\right)$ & .356 & .001 & .42 & 2.28 \\
\hline & 3 slides with space & .63 & .362 & .311 & -.32 & 1.57 \\
\hline & 3 slides with notes & $-1.02(*)$ & .368 & .032 & -1.98 & -.06 \\
\hline \multirow[t]{3}{*}{$\begin{array}{l}3 \text { slides with } \\
\text { space }\end{array}$} & No handouts & .72 & .359 & .188 & -.21 & 1.66 \\
\hline & 6 slides & -.63 & .362 & .311 & -1.57 & .32 \\
\hline & 3 slides with notes & $-1.65(*)$ & .371 & .000 & -2.61 & -.68 \\
\hline \multirow{3}{*}{$\begin{array}{l}3 \text { slides with } \\
\text { notes }\end{array}$} & No handouts & $2.37(*)$ & .365 & .000 & 1.42 & 3.32 \\
\hline & 6 slides & $1.02(*)$ & .368 & .032 & .06 & 1.98 \\
\hline & 3 slides with space & $1.65(*)$ & .371 & .000 & .68 & 2.61 \\
\hline
\end{tabular}

${ }^{*}$ The mean difference is significant at the .05 level.

The following observations are seen in the Table 2:

1. The class receiving the handouts with the optimized thumbnails and presenter's notes performed better than all the other classes. This was statistically significant with $\mathrm{p}$ ranging from .000 to .032 .

2. The class (Group \#2) which was informed that the lecture had 50\% weight on the quiz, did significantly better than the class with no handouts $(\mathrm{p}=.001)$.

3. It is interesting to see that Group \#2 still performed worse than the class with the handout hypothesized to be the best (Group \#4) despite the fact that the specific importance of the lecture was not known to Group \#4.

4. Statistics for Group \#4 were outstanding

a. Variance $=.915$ versus $1.495,2.68,2.78$ for the other groups

b. Skewness $=-1.009$, versus $-.102,-.044$, and -.003 for the other groups

\section{DISCUSSION AND IMPLICATIONS}

\section{Limitations of Study and Future Research}

The effects of different types of presentation handouts on students' learning outcomes were found significant in this study with 120 sampled subjects. Future studies can use even larger sample sizes to replicate this study to further confirm the research findings.

A multiple choice quiz was used, which might have some limitations for assessment; however, it is also an objective tool for assessment of learning outcomes. Prior performance on the quiz used for assessment was found to be randomly distributed. Future studies can use different assessment questions to further examine the effects of presentation handouts on learning outcomes. 


\section{CONCLUSIONS}

This study sought to find the best handout for use during a presentation in the classroom. The handout with optimized thumbnails and presenter's notes facilitates better student performance.

1. The class (Group \#4) with the optimized handout clearly outperformed all other classes with most students consistently scoring the maximum attainable. This explains the dramatically lower variance and higher skewness.

2. The twenty minute lecture in question had a relatively large $(50 \%)$ weight on the quiz that spanned eight hours of instruction. The class (Group \#2) with specific knowledge about the lecture weight still underperformed the group with the best handout. This may show that the handouts with speaker's notes facilitate study in the most optimum way.

3. It might be argued that the handout with lined space for notes should have performed more strongly. This is because note-taking helps the learning experience by forcing the learner's mind to synthesize the lecturer's discourse into relevant points [10]. Nonetheless, the class with the optimized handout significantly $(\mathrm{p}=.000)$ outperformed the handout that provided lined space for note-taking.

The study could be explored further with the following variations: 1) a larger sample size, 2) a longer lecture and/or more challenging content, 3) a larger assessment, and 4) different content (more descriptive and conceptual, less graphical).

\section{REFERENCES}

1. Bonk, C. J. (2002). Research Related to the Effectiveness E-Learning and Collaborative Tools, Chief Learning Officer, pp. 22-24, \& 26-27.

2. D'Alessandro, D. M., Kreiter, C. D. \& Peterson, M. W. (2004). An evaluation of informationseeking behaviors of general pediatricians, Journal of Pediatrics, 113(1), 64-69.

3. Gribble, R. K. \& Haupt, C. (2005). Quantitative and qualitative differences between handout and mailed patient satisfaction surveys, Journal Of Medical Care, 43(3), 276-281.

4. Lundgren, T. D. \& Nantz, K. S. (2003). Student attitudes toward Internet courses: A longitudinal study, Journal Of Computer Information Systems, 43(3), 61-66.

5. McDowell, G. R. (2001). A student-centred learning approach to teaching Soil Mechanics, International Journal Of Engineering Education, 17(3), 255-260.

6. Pryor, B., Butler, J., Boyson, A., \& Barfield, R. L. (1999). Effects of distributing "handouts" during a speech on receivers' inferred information processing, Journal of Perceptual and Motor Skills, 89(1), 145-150.

7. Schuetze, P. (2004). Evaluation of a brief homework assignment designed to reduce citation problems, Journal of Teaching of Psychology, 31(4), 257-259.

8. Tang, P. C. \& Newcomb, C. (1998). Informing patients: A guide for providing patient health information, Journal of the American Medical Informatics Association, 5(6), 563-570.

9. Zakrzewska, J. M., Fry, H. \& Larkin, K. E. (2003). A case study of methods used to tackle a common pedagogic, Journal of Medical Teacher, 25(4), 391-397.

10. Zull, J. E. (2002). The Art of Changing the Brain: Enriching Teaching by Exploring the Biology of Learning, Stylus Publishing (VA). 